\title{
CHINESE ACADEMIC LEADERSHIP FROM THE PERSPECTIVE OF CONFUCIAN VIRTUES AND ITS EFFECTS ON TEACHER COMMITMENT
}

\author{
Shiau Ching Limª , Lei Mee Thien ${ }^{\mathrm{a}^{*}}$ \\ a School of Educational Studies, Universiti Sains Malaysia \\ *Corresponding Author's Email: thienleimee@usm.my
}

\begin{abstract}
The effect of principal leadership on school outcomes is contextually and culturally specific. However, the influence of Chinese academic leadership on teacher commitment has received less attention in the literature. This study aims to examine the direct relationships between Chinese academic leadership and four dimensions of teacher commitment, namely (a) commitment to teaching, (b) commitment to students, (c) commitment to profession, and (d) commitment to school. Data were collected from 260 teachers who worked in 15 National-Type Chinese Primary Schools (NTCPS) in Kota Setar district in Kedah. This study utilised descriptive statistics and partial least squares structural equation modelling approach using WarpPLS 5.0 software for data analysis. Findings revealed the levels of the five dimensions of Chinese academic leadership were moderate. Chinese academic leadership was positively related to commitment to school $(B=0.468, p<.001)$, commitment to students $(B=0.327, p<.001)$, commitment to profession $(B=0.356, p<.001)$, and commitment to teaching $(B=0.275, p<.001)$. Implications and future studies are presented.
\end{abstract}

Keywords: Chinese Academic Leadership, Confucian Virtues, Partial Least Squares Structural Equation Modelling (PLS-SEM), Teacher Commitment.

\section{INTRODUCTION}

Educational leadership studies have expanded remarkably for the past six decades (Gumus, Bellibas, Esen, \& Gumus, 2018; Hallinger \& Kovačević, 2019). A substantial body of empirical research on educational leadership and management was wellreflected in Latin America, Asia, and Africa (Hallinger, 2020; Hallinger \& Kovačević, 2019). Interestingly, researches have recently suggested adding values to educational leadership studies from an indigenous cultural perspective (Brian, 2016; Liu, 2017). This is because the 'hidden influence' of the sociocultural context has a significant impact on school outcomes (Ahmad Bajunid, 1996; Hallinger \& Leithwood, 1996). In fact, the context-specific that bears upon the enactment of principal leadership in different sociocultural contexts has rapidly gained attention in literature, particularly in the Chinese society (e.g., Ng, Nguyen, Wong, \& Choy, 2015; Pan, Nyeu, \& Cheng, 2017; Truong, \& Hallinger, 2017). The literature revealed that most of the school leadership studies in the Chinese society tend to focus on the investigation of predictors of school leadership such as instructional leadership, trust, professional learning community, and teacher commitment and self-efficacy among elementary or high school teachers in mainland China (Ma \& Marion, 2019; Zheng, Yin, \& Lin, 2019).

There is a growth of interesting empirical studies with respect to the influence of principal leadership with the belief that leadership could be strengthened by integrating virtue ethics in the authentic practices of leadership style in the Chinese school context (Solansky et al., 2017; Xu, 2011). With this concern in mind, it is worthy 
to highlight that Chinese leadership practices are strongly influenced by Confucian virtues (Xu, 2011). Specifically, the Confucian virtues such as (a) perfect virtue (仁 rén), (b) righteousness (义 yì), (c) propriety (礼 lii), (d) wisdom (智 zhì), and (e) trustworthiness (信 xìn) are the five fundamental virtues that underlined the human behaviour and action in cultivating harmonious human relationship in the Chinese society (Siah, Ong, Tan, \& Sim, 2015). However, research on the effects of Chinese school leadership from the Confucian virtues on teacher commitment is underexplored in the school leadership literature. With this research gap in mind, this exploratory study seeks to examine the level of Chinese academic leadership in the Malaysian Chinese primary schools. Specifically, this study has extended to examine the effect of Chinese academic leadership on four dimensions of teacher commitment, namely (a) commitment to school, (b) commitment to students, (c) commitment to teaching, and (d) commitment to profession. The current study attempts to address two research questions as follows:

1. What are the levels of Chinese academic leadership in terms of (a) morality, (b) nurturing, (c) communicating, (d) fairness, and (e) administrative competence among the Chinese primary school head teachers?

2. Is there any positive direct effect of Chinese academic leadership on teacher commitment to school, commitment to students, commitment to teaching, and commitment to profession respectively?

\section{LITERATURE REVIEW}

\section{Confucianism}

'The Holy Master' - Confucius is the name of the mound. What he knows best is 'teaching in accordance with his aptitude' and 'teaching without class'. His old central thought, benevolence, is like a bright light in the darkness, lighting one's wisdom and showing one's ignorance. In the history of China, Confucius has affected the culture and history of China as a whole and even the future of mankind around the world (Rarick, 2007). Confucian ethics is composed of four texts, which are 'The Analects', 'The Mencius', 'The Great Learning', and 'The Doctrine of the Mean' (Hackett \& Wang, 2012). Wang (2011) stated that 'Confucius provides a system of virtue ethics'. In 'The Analects', Confucius addresses leadership issues in his discussion of 'rulers', commenting that virtues enable 'rulers' to fulfil their roles well (Hackett \& Wang, 2012).

Hackett and Wang (2012) explained both Confucius and Mencius contended that a virtue is a state of human character (associated with the mind) that guides people to do 'good', a virtue is expressed voluntarily, virtues are present to some degree at birth and are maintained through continuous practice and once lost, virtues can be reacquired through self-learning and practice. Mak and his associates (2014) clarified that the Confucian philosophical tradition regards individuals' moral self-cultivation as the foundation of order in society: cultivate oneself, put the family in order, govern the state, pacify the world (修身齐家治国平天下 xiu shen qi jia zhi guo ping tian xia), and family comes before work. When a person cultivates himself or herself morally and is a virtuous person (君子 junzi), he or she will be able to manage his or her family; only when the person can manage his or her family well, can that person be successful in a career. Tjeldvoll (2011) inferred that Confucian philosophical tradition regarding 
individuals' moral self-cultivation brings us to a key concept in Confucian thinking (道 Dao), namely the ethical ideal of a good human life as a whole.

\section{Confucian Values and Chinese Academic Leadership}

The Confucian leader is expected to achieve self-control and be a model for others to follow. For Confucius, the leader should study, should have the expertise, talent, and ability, and should be willing to serve the common good. Confucius endowed talent with a moral connotation and insisted that only talented individuals with moral conduct are selected as leaders. Chen (1997) stated humanism comes out as a central dimension of Confucianism founded on three key principles: love for others (仁 ren), fairness (义 yi), and proper behaviour (礼 li). These three principles were originally proposed by Confucius to remind the kings in his time to overcome the 'way of despot' or the way of force, by the 'kingly way' or the way of moral power and humane government. These are the commentaries that Confucian leaders are practising in the three leadership principles. Hence, Confucianism is important to practise Confucian philosophy in the Chinese society that is related to leadership. Lin and Clair (2007) pointed out that an important quality of Confucian values is to maintain good relationships with followers, creating a feeling of the family where pleasures and sorrows are shared.

Despite the literature revealing an increasing amount of enquiry into Chinese leadership from the lens of Confucian virtues in the non-educational context (e.g., Hunsaker, 2017; Lin, Ho, \& Lin, 2013), research on Chinese academic leadership in relation to Confucian virtues is still underexplored in the school leadership literature. In the education setting, Chinese academic leadership is referred to as the beliefs and attitudes of leaders in influencing the activities of teachers in their effort towards efficient school improvement and goal achievement, which is related or connected with studying and thinking, not with practical skills in the Chinese society (Xu, 2011). $\mathrm{Xu}(2011)$ is one of the limited studies that underscored Chinese academic leadership from the lens of Confucian virtues in the Hong Kong education context with the belief that Confucianism has a large impact on Chinese leaders. Xu (2011) has proposed a five-factor model of Chinese academic leadership based on Confucian virtues. The five factors or dimensions of Chinese academic leadership are (a) morality, (b) nurturing, (c) communicating, (d) fairness, and (e) administrative competence. Morality is operationalised as the extent to which leaders are supposed to show self-discipline and moral character and serve as a moral model for followers. Nurturing refers to the extent to which leaders are making efforts to support and help followers grow and succeed in their work. Communicating refers to the extent of the leaders' communication behaviours when interacting with followers. Fairness refers to the extent to which leaders display fairness in distributing resources to achieve harmony among followers. Meanwhile, administrative competence refers to the extent to which leaders are competent in managing administrative affairs. The current study has adopted Xu's (2011) conceptualisation of Chinese academic leadership.

\section{Teacher Commitment}

Commitment is defined as 'a bond or linking of the individual to the organisation' (Mathieu \& Zajac, 1990, p. 171). On the other hand, organisational commitment is referred to as 'the relative strength of an individual's identification with and involvement in a particular organisation' (Mowday, Steers, \& Porter, 1979, p. 226). In an educational setting, committed teachers are commonly described as those who 
are more hard-working, devote more time to school activities, have better work performance, and exert more effort beyond personal needs (Reyes, 1990; Thien \& Razak, 2014). Apart from that, the committed teachers always put their students' needs, requirements, and benefits first, which meet the needs of each student by providing a variety of unique teaching techniques and methods. In other words, the committed teachers are reported having strong psychological ties to their school, their students, or their teaching subject matter (Firestone \& Pennell, 1993). In line with this concern, Thien, Razak, and Ramayah (2014) have conceptualised teacher commitment as a multidimensional construct with its four underlying dimensions: (a) commitment to school, (b) commitment to students, (c) commitment to teaching, and (d) commitment to profession.

The current study has adopted these four dimensions of teacher commitment as these dimensions are important in educational settings. These teacher commitment dimensions are necessary to accomplish the school objectives, improve teachers' professionalism, and pursue changes in teachers' practices.

Teachers who are highly committed to their school are expected to engage in school activities to achieve the school goals, exert considerable effort beyond minimal expectations, and remain working within the organisation. Teacher commitment to school is conceptualised as teachers' belief and acceptance of the goals and values of the school, teachers' efforts for the actualisation of these goals and values, and the teachers' strong desires to keep up membership in the school (Thien \& Razak, 2014).

Rosenholtz (1989) asserted that teachers who are committed to their students are likely to be positively engaged with their students, work harder to make classroom activities more meaningful, and introduce new ways of learning. Thien et al. (2014) conceptualised teacher commitment to students as teachers' involvement or responsibility in student learning. Teachers attempt to encourage and engage students as they know that not every child will learn in the same way.

Coladarci (1992) described commitment to teaching as an indicator of a teacher's psychological attachment to the teaching profession. Commitment to teaching reflects a high degree of psychological attachment with teachers' duties in their classroom (Coladarci, 1992). Thien et al. (2014) conceptualised teacher commitment to teaching as teachers' willingness to be engaged in teaching. Commitment to teaching is further operationalised by the degree to which the teaching profession provided teachers that promotes their professional development and growth (Thien et al., 2014).

Somech and Bogler (2002) stated that teacher commitment to profession involves an affective attachment to the profession or occupation that is associated with personal identification and satisfaction. Teacher commitment to profession is conceptualised as the strength of teacher motivation and involvement to work and to improve professional skills, knowledge, and teaching abilities (Thien et al., 2014). The teacher's commitment to profession is affected by the teacher's identity and job satisfaction.

\section{Relationship between the Chinese Leadership and Teacher Commitment}

Voluminous research has investigated the relationship between principal leadership and teacher commitment either in the Western or non-Western societies (Geijsel, Sleegers, Leithwood, \& Jantzi, 2003; Hallinger \& Lu, 2014; Hallinger, Hosseingholizadeh, Hashemi, \& Kouhsari, 2018; Pietsch, Tulowitzki, \& Koch, 2019). 
Previous studies in this domain have affirmed that various types of leadership, including instructional, transformational, and distributed leadership, have significant and positive effects on teacher commitment (Hallinger \& Lu, 2014; Marshall, 2015).

In contrast, research on Chinese academic leadership and teacher commitment is limited in the literature. A Singaporean study by Wang, Gurr, and Drysdale (2016) found that Chinese school leaders' personal qualities, beliefs, and values contributed significantly to leading successful schools. Wang et al. (2016) further elaborated that successful school leaders have the characteristics of caring, respecting, and being considerate to their subordinates. These leadership attributes are demonstrated through their behaviours, including ways of communicating and handling administrative tasks of their leadership practices (Wang et al., 2016). On the other hand, Siah et al. (2015) contended that Chinese cultural principles embraced Confucian virtues as of paramount value in enhancing the effectiveness of the Malaysian Chinese school context. As teachers are the key agents in ensuring school reform (Fullan, 2008), it makes sense to hypothesise that Chinese academic leadership that is strongly influenced by the Confucian values could impact on teacher commitment.

Therefore, Xu's (2011) five dimensions of Chinese academic leadership are expected to have significant and positive effects on the four dimensions of teacher commitment. This study postulated four hypotheses as follows:

$\mathrm{H} 1$ : There is a positive relationship between Chinese academic leadership and commitment to school.

H2: There is a positive relationship between Chinese academic leadership and commitment to students.

H3: There is a positive relationship between Chinese academic leadership and commitment to teaching.

$\mathrm{H} 4$ : There is a positive relationship between Chinese academic leadership and commitment to profession.

\section{METHOD}

\section{Sample}

This study employed cross-sectional quantitative research design and convenience sampling procedure. The targeted population is National-Type Chinese Primary schools (NTCPS) teachers in Kedah. NTCPS embraced the Chinese culture and contributed to the preservation of values and beliefs of the Chinese community. The Malaysian Chinese ethnicity and culture are linked to Chinese roots through education that embraced Confucian values, namely loyalty and morality, courage and righteousness, faithfulness and honesty, benevolence and compassion, conscientiousness and altruism as well as considerateness and courtesy (Siah et al., 2015). It is for this reason the current study selected NTCPS as the school sample.

There are 23 NTCPS in the Kota Setar district. Fifteen schools were selected as the sample of the study. Eight NTCPS that are categorised as low-enrolment schools (Sekolah Kurang Murid) were excluded from the targeted population. The exclusion of the low-enrolment schools is due to the following reason. The increase of nonChinese students in NTCPS from year to year has indicated that NTCPS with low 
enrolment (SKM) are more racially mixed (https://www.malaysia.gov.my/portal/content/29468). As such, it is expected that the Chinese culture in NTCPS with low enrolment is somewhat different compared to NTCPS with high enrolment. Therefore, this study did not include NTCPS with low enrolment as the school sample.

All the head teachers in the 15 selected NTCPS are Chinese. There are 428 teachers who are currently working in the 15 selected NTCPS. However, the non-Chinese and temporary teachers were excluded from participating in this study. This study has excluded 60 temporary and non-Chinese teachers from the total number of 428 teachers. This made up 368 teacher sample. However, only 260 respondents returned the computed questionnaire. This indicated a response rate of $71 \%$. Despite the relative low return rate, the sample size of 260 is considered sufficient as the minimum sample size requirement is 160 based on the calculation of inverse square root method in partial least squares structural equation modeling (PLS-SEM) (Kock \& Hadaya, 2018).

The sample demographics showed that the dominant group was female teachers (231), whereas only 29 out of the sample were male teachers. The majority of the respondents were from the age group of 51 years and above (85), followed by 41 to 50 years (79). Meanwhile, there were 37 and 59 respondents aged 30 years and below, and 31 to 40 years respectively.

\section{Instrumentation}

Xu's (2011) Chinese academic leadership scale was used to measure the five dimensions of Chinese academic leadership: (a) morality (4 items), (b) nurturing (8 items), (c) communicating (7 items), (d) fairness (4 items), and (e) administrative competence ( 8 items). The items are statements on the behaviour of the head teacher of their school. Teachers perceived their head teachers' enactment on Chinese academic leadership from five perspectives: (a) morality, (b) nurturing, (c) communicating, (d) fairness, and (e) administrative competence by providing their level of agreement based on a four-point Likert scale $(1=$ strongly disagree to $4=$ strongly agree). The convergent and discriminant validity of each dimension were evident based on the confirmatory factor analysis presented by Xu (2011).

This study has adapted Thien et al.'s (2014) teacher commitment scale to measure (a) commitment to school (4 items), (b) commitment to students (4 items), (c) commitment to teaching ( 3 items), and (d) commitment to profession (4 items). Responses were rated on a six-point Likert scale ranging from 1 (strongly disagree) to 6 (strongly agree). The internal consistency of these four dimensions ranged from 0.71 to 0.89 , indicating the reliability was satisfactory (Thien et al., 2014). Overall, a total of 46 items were used to measure both the Chinese academic leadership and teacher commitment scales.

\section{Data Collection}

This study secured consent from the authority at both the ministry and state levels. The questionnaires were distributed to the sample after getting agreement from the head teachers. Participation by the respondents was strictly voluntary. The purpose of the study was notified to the respondents. The questionnaires were collected within two weeks. 


\section{Data Analysis}

This study employed descriptive statistics with IBM SPSS 24.0 to examine the level of the five dimensions of Chinese academic leadership: (a) morality, (b) nurturing, (c) communicating, (d) fairness, and (e) administrative competence. Partial least squares structural equation modelling (PLS-SEM) with WarpPLS 5.0 software (Kock, 2015) was used to examine the relationships between Chinese academic leadership and the four dimensions of teacher commitment. PLS-SEM was applied due to its superiority in dealing with a second-order construct. In this study, Chinese academic leadership is a second-order construct with five first-order constructs, namely (a) morality, (b) nurturing, (c) communicating, (d) fairness, and (e) administrative competence. This study utilised a two-stage approach to examine the direct effect of Chinese academic leadership on the four dimensions of teacher commitment: assessment of the measurement model and structural model.

At stage 1, the assessment of the measurement model was conducted to establish the convergent and discriminant validity between the constructs and its respective items (Hair, Hult, Ringle, \& Sarstedt, 2017). The assessment of the measurement model was conducted at two levels to test the first-order constructs and second-order constructs. Convergent validity refers to the extent to which an item correlates with other items of the same construct. Meanwhile, discriminant validity refers to the extent to which a construct is truly distinct from other constructs. Convergent validity includes the assessment of (a) internal consistency as indicated by estimation of composite reliability (CR), (b) indicator reliability in terms of loading values, and (c) average variance extracted (AVE). According to Hair et al. (2017), the threshold values of CR is 0.70 , the loading value is 0.70 , and AVE is 0.50 and above (Hair et al., 2017). This study utilised Fornell and Larcker's (1981) criterion to establish the discriminant validity. At stage 2, the assessment of the structural model was conducted to examine the relationships between Chinese academic leadership and the four dimensions of teacher commitment. Path coefficients, explained variance $\left(R^{2}\right)$, and effect size $\left(f^{2}\right)$ were examined in the structural model (Hair et al., 2017).

\section{RESULTS}

\section{Descriptive Statistics}

Table 1 shows the mean and standard deviation values of the five dimensions of Chinese academic leadership. The mean values of these five dimensions were at moderate level based on the four-point Likert scale responses ranging from 0 (strongly disagree) to 3 (strongly agree). The highest mean value was administrative competence $(M=2.252, S D=0.472)$ and the lowest mean value was morality $(M=$ $2.252, S D=0.472)$. Meanwhile, the mean values of the remaining three dimensions, namely nurturing $M=2.184, S D=0.444)$, communicating $(M=2.104, S D=0.439)$ and fairness $(M=2.192, S D=0.552$ ) were slightly different.

\section{Assessment of Measurement Model}

The first analysis showed that 11 items that measured the five dimensions of Chinese academic leadership needed to be excluded due to the loading values below the cutoff value of 0.70 . These 11 items are MOR4, NUR 3, NUR4, COM1, COM5, COM6, COM7, FAR2, ADM1, ADM2, and ADM6. Similarly, three items (CTS 1, CTS4, CTU4) were excluded from the respective dimension of teacher commitment, with the loading values smaller than 0.70 . The second analysis was rerun with the remaining 31 items. 
Table 1: Descriptive Statistics of Chinese Academic Leadership

\begin{tabular}{lcc}
\hline Dimension & Mean & Standard Deviation \\
\hline Morality & 2.037 & 0.333 \\
Nurturing & 2.184 & 0.444 \\
Communicating & 2.104 & 0.439 \\
Fairness & 2.192 & 0.552 \\
Administrative competence & 2.252 & 0.472 \\
\hline
\end{tabular}

Table 2 shows that all the CR and AVE values of each first-order construct were larger than the threshold of 0.70 and 0.50 respectively. All the loading values of each respective first-order construct were found larger than 0.70 except Item CTT3. However, Item CTT3 was retained as the CR and the AVE values of commitment to teaching were larger than the thresholds of 0.70 and 0.50 respectively.

Table 2: Result of Measurement Model (First-Order Constructs)

\begin{tabular}{|c|c|c|c|c|c|c|c|c|c|c|c|}
\hline & MOR & NUR & $\mathrm{COM}$ & FAR & ADM & CTS & стU & CTT & CTP & $C R$ & AVE \\
\hline \multicolumn{12}{|c|}{ Morality } \\
\hline MOR1 & 0.846 & & & & & & & & & 0.914 & 0.780 \\
\hline MOR2 & 0.910 & & & & & & & & & & \\
\hline MOR3 & 0.893 & & & & & & & & & & \\
\hline \multicolumn{12}{|c|}{ Nurturing } \\
\hline NUR1 & & 0.871 & & & & & & & & 0.862 & 0.758 \\
\hline NUR4 & & 0.871 & & & & & & & & & \\
\hline \multicolumn{12}{|c|}{ Communicating } \\
\hline $\mathrm{COM} 1$ & & & 0.918 & & & & & & & 0.948 & 0.819 \\
\hline $\mathrm{COM} 2$ & & & 0.921 & & & & & & & & \\
\hline $\mathrm{COM} 3$ & & & 0.935 & & & & & & & & \\
\hline $\mathrm{COM} 4$ & & & 0.843 & & & & & & & & \\
\hline \multicolumn{12}{|c|}{ Fairness } \\
\hline FAR1 & & & & 0.878 & & & & & & 0.932 & 0.820 \\
\hline FAR3 & & & & 0.923 & & & & & & & \\
\hline FAR4 & & & & 0.915 & & & & & & & \\
\hline \multicolumn{12}{|c|}{$\begin{array}{l}\text { Administrative } \\
\text { competence }\end{array}$} \\
\hline $\mathrm{ADM} 3$ & & & & & 0.891 & & & & & 0.928 & 0.720 \\
\hline $\mathrm{ADM} 4$ & & & & & 0.902 & & & & & & \\
\hline $\mathrm{ADM} 5$ & & & & & 0.827 & & & & & & \\
\hline ADM7 & & & & & 0.876 & & & & & & \\
\hline ADM8 & & & & & 0.737 & & & & & & \\
\hline \multicolumn{12}{|c|}{ Commitment to school } \\
\hline CTS2 & & & & & & 0.936 & & & & 0.934 & 0.875 \\
\hline CTS3 & & & & & & 0.936 & & & & & \\
\hline \multicolumn{12}{|c|}{ Commitment to students } \\
\hline CTU1 & & & & & & & 0.838 & & & 0.902 & 0.755 \\
\hline $\mathrm{CTU} 2$ & & & & & & & 0.913 & & & & \\
\hline CTU3 & & & & & & & 0.854 & & & & \\
\hline \multicolumn{12}{|c|}{ Commitment to teaching } \\
\hline $\mathrm{CTT1}^{-1}$ & & & & & & & & 0.706 & & 0.771 & 0.529 \\
\hline $\mathrm{CTT} 2$ & & & & & & & & 0.784 & & & \\
\hline $\mathrm{CTT3}$ & & & & & & & & 0.690 & & & \\
\hline \multicolumn{12}{|c|}{$\begin{array}{l}\text { Commitment to } \\
\text { profession }\end{array}$} \\
\hline CTP1 & & & & & & & & & 0.876 & 0.915 & 0.782 \\
\hline $\mathrm{CTP} 2$ & & & & & & & & & 0.886 & & \\
\hline CTP3 & & & & & & & & & 0.891 & & \\
\hline
\end{tabular}


Table 3 shows that all the square root values (see bold figures) of each first-order construct are larger than the correlation values between each respective construct with other first-order constructs. Hence, the discriminant validity of first-order constructs was established.

Table 3. Fornell and Larcker's (1981) Criterion (First-Order Constructs)

\begin{tabular}{cccccccccc}
\hline & MOR & NUR & COM & FAR & ADM & CTS & CTU & CTT & CTP \\
\hline MOR & $\mathbf{0 . 8 8 3}$ & & & & & & & & \\
NUR & 0.653 & $\mathbf{0 . 8 7 1}$ & & & & & & & \\
COM & 0.735 & 0.738 & $\mathbf{0 . 9 0 5}$ & & & & & & \\
FAR & 0.664 & 0.699 & 0.825 & $\mathbf{0 . 9 0 6}$ & & & & & \\
ADM & 0.703 & 0.718 & 0.789 & 0.757 & $\mathbf{0 . 8 4 9}$ & & & & \\
CTS & 0.321 & 0.390 & 0.448 & 0.423 & 0.359 & $\mathbf{0 . 9 3 6}$ & & & \\
CTU & 0.246 & 0.322 & 0.160 & 0.110 & 0.121 & 0.400 & $\mathbf{0 . 8 6 9}$ & & \\
CTT & 0.170 & 0.112 & 0.129 & 0.027 & 0.095 & 0.287 & 0.520 & $\mathbf{0 . 7 2 8}$ & \\
CTP & 0.348 & 0.256 & 0.272 & 0.323 & 0.245 & 0.247 & 0.311 & 0.062 & $\mathbf{0 . 8 8 4}$ \\
\hline
\end{tabular}

Note: The diagonal values represent the square root of AVE (in bold).

Table 4 shows that the convergent validity of the second-order construct of Chinese academic leadership was established, with the loading values of the first-order constructs larger than 0.70 . The CR and AVE values are larger than the threshold of 0.70 and 0.50 respectively.

Table 4: Measurement Model (Second-Order Construct)

\begin{tabular}{ccccc}
\hline Second-Order Construct & First-Order Construct & Loading & CR & AVE \\
\hline Chinese academic leadership & MOR & 0.846 & 0.948 & 0.783 \\
& NUR & 0.859 & & \\
& COM & 0.926 & & \\
& FAR & 0.894 & & \\
& ADM & 0.898 & & \\
\hline
\end{tabular}

Note: The first-order constructs were converted into latent variable scores.

Table 5 shows that the square root values of AVE of Chinese academic leadership and the four dimensions of teacher commitment (CTS, CTU, CTS, and CTT) were larger than the correlation values between the respective construct and other constructs. Hence, the discriminant validity of the second-order construct was established.

Table 5: Fornell and Larcker's (1981) Criterion (Second-Order Construct)

\begin{tabular}{llllll}
\hline & CAL & CTS & CTU & CTT & CTP \\
\hline CAL & $\mathbf{0 . 8 8 5}$ & & & & \\
CTS & 0.440 & $\mathbf{0 . 9 3 6}$ & & & \\
CTU & 0.214 & 0.400 & $\mathbf{0 . 8 6 9}$ & & \\
CTT & 0.120 & 0.287 & 0.520 & $\mathbf{0 . 7 2 8}$ & \\
CTP & 0.325 & 0.247 & 0.311 & 0.062 & $\mathbf{0 . 8 8 4}$ \\
\hline
\end{tabular}

Note: The diagonal values represent the square root of AVE (in bold).

\section{Assessment of Structural Model}

Table 6 shows that Chinese academic leadership has a positive and significant relationship with commitment to school $(B=0.468, p<.001)$, commitment to students $(B=0.327, p<.001)$, commitment to teaching $(B=0.275, p<.001)$, and commitment to profession ( $B=0.356, p<.001)$. According to Cohen (1988), the effect size with the threshold of $0.02,0.15$, and 0.35 represent weak, moderate, and strong impact of the 
independent variable on the dependent variable. Table 6 shows that Chinese academic leadership has a moderate impact on commitment to school $\left(f^{2}=0.219\right)$, followed by commitment to profession $\left(f^{2}=0.127\right)$. However, Chinese academic leadership has a weak impact on commitment to students $\left(f^{2}=0.107\right)$ and commitment to teaching $\left(f^{2}=0.076\right)$.

Table 6: Hypothesis Testing

\begin{tabular}{lllccl}
\hline Hypothesis & Beta & SE & $p$ value & Effect Size & Decision \\
\hline H1: CAL-> CTS & 0.468 & 0.057 & $<.001$ & 0.219 & Supported \\
H2: CAL-> CTU & 0.327 & 0.059 & $<.001$ & 0.107 & Supported \\
H3: CAL-> CTT & 0.275 & 0.059 & $<.001$ & 0.076 & Supported \\
H4: CAL-> CTP & 0.356 & 0.058 & $<.001$ & 0.127 & Supported \\
\hline
\end{tabular}

Figure 1 shows that Chinese academic leadership contributed to the highest variance explained on commitment to school (about 22\%), followed by $13 \%$ of variance explained on commitment to profession. However, Chinese academic leadership contributed about $11 \%$ and $8 \%$ of variance explained on commitment to students and commitment to teaching respectively.

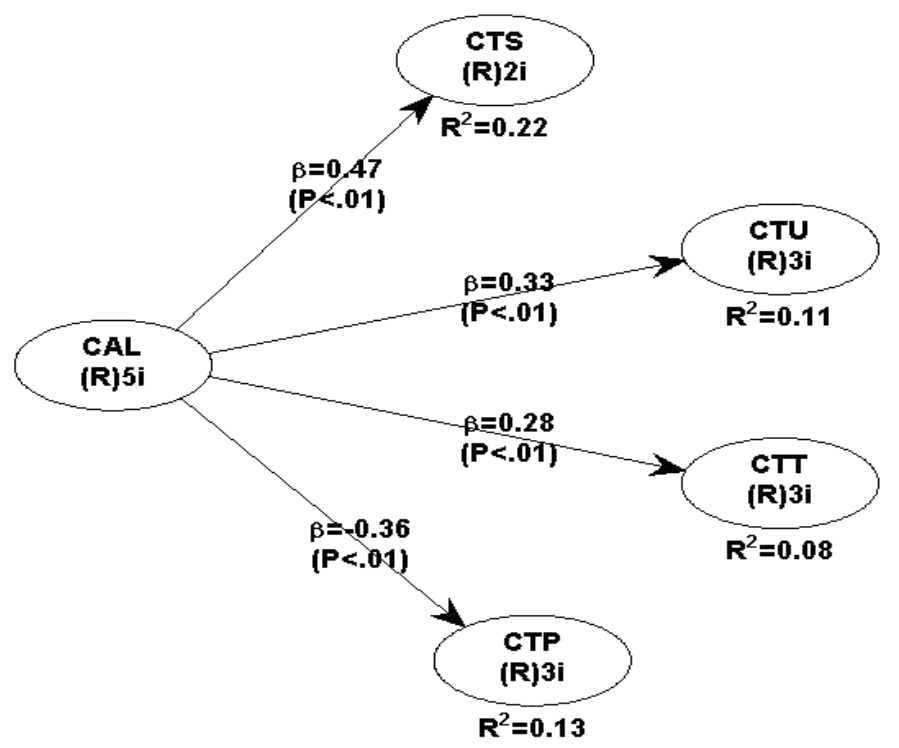

Figure 1. Structural Model

\section{DISCUSSION AND CONCLUSION}

The scarcity of research on school leadership from the perspective of Confucian virtues in the educational leadership literature has prompted the current study to investigate the effects of Chinese academic leadership on teachers' commitment to school, commitment to students, commitment to teaching, and commitment to profession in the Chinese primary schools. The current study informed several important findings.

Chinese school leaders exhibited a moderate level of all the five dimensions of Chinese academic leadership. Such findings could be due to the influence of a highly centralised education system in Malaysia on the ways of practising leadership in the Chinese primary schools. The top-down education policy delivery system might restrict school leaders to implement value or humanity-based leadership in the school. 
The rigid bureaucratic system at the school level could be a barrier to the successful practices of value-based leadership. Concerning the rigid bureaucracy in the Malaysian education system, distributed leadership that involves interaction and collaboration among school leaders and teachers may dominate ways of leading the school organisation instead of value-based leadership (Thien, 2019). Apart from that, as stated in the Malaysia Education Blueprint 2013-2025 (Ministry of Education, 2013), instructional and distributed leadership are relatively prioritised in enhancing the Malaysian principal leadership compared to value-based leadership.

Extending the previous Western studies in this domain (Geijsel et al., 2003; Hallinger \& Lu, 2014; Hallinger et al., 2018), this current study has added the knowledge base in literature with Chinese academic leadership having a significant direct effect on the four dimensions of teacher commitment. The findings implied that Chinese head teachers who are practising Confucian virtues in terms of morality, nurturing, communicating, fairness, and administrative competence are pivotal factors in committing teachers towards school, students, teaching, and profession. It could be claimed that school leaders who stress the Confucian virtues have provided a conducive social climate that could have a beneficial effect on teacher learning, classroom practice, and student attainment. The conducive social climate in school could, in turn, facilitate teacher commitment through school routine activities.

Specifically, this study has supported that Chinese school leaders who serve as a moral model for teachers, competent in managing administrative affairs, have good communication with teachers, and are fair in distributing resources could foster the development of an emotional attachment among teachers. As a result, teachers who feel more affectively attached to the schools are likely motivated to perform their best, particularly from the perspective of profession and school (Meyer \& Allen, 1997). It can be drawn that teachers who work with Chinese academic leadership embedded with the Confucian values are more involved, motivated, and committed to their schools. Teachers are likely committed to their profession in terms of professional skills, knowledge, and teaching abilities when the school leaders make the effort to support and help teachers grow and succeed in their work.

However, the weak impact of Chinese academic leadership on teacher commitment to teaching and teacher commitment to students deserves further attention. The weak relationship between school leadership and teacher organisational commitment could be indirect. The structural relationship between school leadership and teacher commitment might be influenced by potential mediators, including socio-affective factors and teachers' psychological capital (Berkovich \& Bogler, 2020). Mediators related to socio-affective factors and teachers' psychological capital were not included in the current study.

This study has practical implications. Confucian virtues of being benevolent and fostering the feeling of brotherhood or sisterhood are imperative to nurture conducive school condition and subsequently facilitate teacher commitment. Therefore, value-based school leadership skills are required in nurturing these conducive school conditions. Besides, an understanding of the effects of Chinese academic leadership on enhancing teachers' commitment would help school leaders to identify the appropriate leadership practices that could optimise the organisational outcomes. This study has theoretical implications for the new knowledge of Chinese academic leadership and teacher commitment outside the Western societies. This study contributes towards the theoretical understanding of the underlying 
mechanisms of the leadership-teacher commitment relationship by highlighting the Confucian virtues. The findings have further informed the need for strengthening Chinese academic leadership among the school leadership, particularly in the Malaysian Chinese primary schools.

This study has some limitations that could inform direction for future studies. First, the sample selection is limited to one district and the sample size is somewhat less representative to generalise the findings to a broader context. Thus, future studies could include larger and more representative samples to provide generalisable empirical findings. Apart from that, the claim that the primary school leaders in all NTPCS practised Chinese academic leadership could be further explored using indepth investigation with qualitative research method in future studies. The empirical findings between Chinese academic leadership and the four dimensions of teacher commitment could be further scrutinised by using qualitative research design with interview technique. Furthermore, the psychometric properties of the Chinese academic leadership and teacher commitment scales could be further examined so that appropriate and validated scales could be used in the indigenous culture in future studies. As the relationship between Chinese academic leadership and teacher commitment could be indirect, future studies could include theoretically supported mediators such as teacher social capital as the mediator in the current structural model (Berkovich \& Bogler, 2020). In addition to the undertaken five dimensions of Confucian values in this study, other characteristics of Confucian principle of leadership such as paternalistic leadership that is combined with the fatherly benevolence could be the possible factors that made teachers committed to their work in schools. Hence, future studies could investigate how paternalistic leadership could influence teacher commitment.

Overall, the current study is one of the very limited studies to examine the effect of Chinese academic leadership and teacher commitment in the Malaysian Chinese education context. This study has provided the fundamental empirical evidence to be referred and extended in both the local and international research contexts. In essence, this study has contributed to providing value-added empirical findings based on the perspective of Confucian virtues in the educational leadership literature.

\section{REFERENCES}

Ahmad Bajunid, I. (1996). Preliminary explorations of indigenous perspectives of educational management: The evolving Malaysian experience. Journal of Educational Administration, 34(5), 50-73. doi:10.1108/09578239610148278

Berkovich, l., \& Bogler, R. (2020). Conceptualising the mediating paths linking effective school leadership to teachers' organisational commitment. Educational Management Administration \& Leadership, 1-20. doi:10.1177/1741143220907321

Brian, L. (2016). Effective leadership today - character not just competence. Strategy \& Leadership, 44(1), 20-29. doi:10.1108/SL-11-2015-0081

Chen, S. C. (1997). The organismic tenet of Chinese philosophy: A comparison of trends in western and Chinese thought. In H. L. Cheng (Ed.), New essays in Chinese philosophy (pp. 139-151). New York: Peter Lang.

Coladarci, T. (1992). Teachers' sense of efficacy and commitment to teaching. The Journal of Experimental Education, 60(4), 323-337. doi:10.1080/00220973.1992.9943869 
Firestone, W. A., \& Pennell, J. R. (1993). Teacher commitment, working conditions, and differential incentive policies. Review of Educational Research, 63(4), 489-525. doi: 10.3102/00346543063004489

Fornell, C., \& Larcker, D. F. (1981). Evaluating structural equation models with unobservable variables and measurement error. Journal of Marketing Research, 18(1), 39-50. doi: 10.1177/002224378101800104

Fullan, M. (2008). The six secrets of change: What the best leaders do to help their organizations survive and thrive. Thousand Oaks, CA: Jossey-Bass.

Geijsel, F., Sleegers, P., Leithwood, K., \& Jantzi, D. (2003). Transformational leadership effects on teachers' commitment and effort toward school reform. Journal of Educational Administration, 41(3), 228-256. doi:10.1108/09578230310474403

Gumus, S., Bellibas, M. S., Esen, M., \& Gumus, E. (2018). A systematic review of studies on leadership models in educational research from 1980 to 2014. Educational Management Administration \& Leadership, 46(1), 25-48. doi:10.1177/1741143216659296

Hackett, R. D., \& Wang, G. (2012). Virtues and leadership: An integrating conceptual framework founded in Aristotelian and Confucian perspectives on virtues. Management Decision, 50(5), 868-899. doi:10.1108/00251741211227564

Hallinger, P. (2020). Science mapping the knowledge base on educational leadership and management from the emerging regions of Asia, Africa and Latin America, 1965-2018. Educational Management Administration \& Leadership, 48(2), 209-230. doi:10.1177/1741143218822772

Hallinger, P., \& Lu, J. F. (2014). Modeling the effects of principal leadership teacher commitment and school capacity on teacher professional learning in Hong Kong primary schools. School Leadership and Management, 35(5), 481-501. doi:10.1080/13632434.2014.938039

Hallinger, P., Hosseingholizadeh, R., Hashemi, N., \& Kouhsari, M. (2018). Do beliefs make a difference? Exploring how principal self-efficacy and instructional leadership impact teacher efficacy and commitment in Iran. Educational Management Administration \& Leadership, 46(5), 800-819. doi:10.1177/1741143217700283

Hallinger, P., \& Kovačević, J. (2019). Science mapping the knowledge base in educational leadership and management: A longitudinal bibliometric analysis, 1960 to 2018. Educational Management Administration \& Leadership. doi:10.1177/1741143219859002

Hallinger, P., \& Leithwood, K. (1996). Culture and leadership in educational administration. Journal of Educational Administration, 34(5), 4-11.

Hair, J. F., Jr., Hult, G. T. M., Ringle, C., \& Sarstedt, M. (2017). A primer on partial least squares structural equation modeling (PLS-SEM) (2nd ed.). Thousand Oaks, CA: SAGE Publications, Inc.

Hunsaker, W. D. (2017). Spiritual leadership and organizational citizenship behavior: Exploring the conditional effects of self-determination and Confucian mindset. International Journal of Business and Society, 18(3), 485-502.

Kock, N. (2015). Warp PLS 5.0 user manual. Laredo, TX: ScriptWarp Systems.

Kock, N., \& Hadaya, P. (2018). Minimum sample size estimation in PLS-SEM: The inverse square root and gamma-exponential methods. Information Systems Journal, 28(1), 227-261. doi: 10.1111/isj.12131

Lin, C., \& Clair, R. P. (2007). Measuring Mao Zedong thought and interpreting organizational communication in China. Management Communication Quarterly, 20(4), 395-429. doi:10.1177/0893318907299177 
Lin, L.-H., Ho, Y.-L., \& Lin, W.-H. E. (2013). Confucian and Taoist work values: An exploratory study of the Chinese transformational leadership behavior. Journal of Business Ethics, 113, 91-103. doi:10.1007/s10551-012-1284-8

Liu, P. (2017). Comparing Chinese and Canadian transformational school leadership practices: A cultural analysis. International Studies in Educational Administration (Commonwealth Council for Educational Administration \& Management), 45(1), 38-54.

Ng, F. S. D., Nguyen, T. D., \& Wong, K. S. B., \& Choy, K. W. W. (2015). Instructional leadership practices in Singapore. School Leadership and Management, 35(4), 388-407. doi:10.1080/13632434.2015.1010501

Ma, X., \& Marion, R. (2019). Exploring how instructional leadership affects teacher efficacy: A multilevel analysis. Educational Management Administration \& Leadership, OnlineFirst, 1-20. doi: 10.1177/1741143219888742

Mak, A., Cheung, L., Mak, A., \& Leung, L. (2014). Confucian thinking and the implications for sustainability in HRM. Asia-Pacific Journal of Business Administration, 6(3), 173-189, doi:10.1108/APJBA-02-2014-0029

Marshall, I. A. (2015). Principal leadership style and teacher commitment among a sample of secondary school teachers in Barbados. Journal of Arts and Humanities, 4(5), 43-58.

Mathieu, J. E., \& Zajac, D. M. (1990). A review and meta-analysis of the antecedents, correlates, and consequences of organisational commitment. Psychological Bulletin, 108(2), 171-194. doi: 10.1037//0033-2909.108.2.171

Meyer, J. P., \& Allen, N. J. (1997). Commitment in the workplace: Theory, research and application. Thousand Oaks, CA: SAGE Publications, Inc.

Ministry of Education Malaysia [MOE]. (2013). Malaysia Education Blueprint 20132025 (Preschool to post-secondary education). Putrajaya: Ministry of Education Malaysia.

Mowday, R. T., Steers, R. M., \& Porter, L. W. (1979). The measurement of organizational commitment. Journal of Vocational Behavior, 14(2), 224-247. doi:10.1016/0001-8791(79)90072-1

Pan, H. L. W., Nyeu, F. Y., \& Cheng, S. H. (2017). Leading school for learning: Principal practices in Taiwan. Journal of Educational Administration, 55(2), 168-185.

Pietsch, M., Tulowitzki, P., \& Koch, T. (2019). On the differential and shared effects of leadership for learning on teachers' organizational commitment and job satisfaction. A multilevel perspective. Educational Administration Quarterly, 55(5), 705-741. doi: 10.1177/0013161X18806346

Rarick, C. A. (2007). Confucius on management: Understanding Chinese cultural values and managerial practices. Journal of International Management Studies, 2(2), 22-28.

Reyes, P. (1989). The relationship of autonomy in decision making to commitment to school and job satisfaction: A comparison between public school teachers and mid-level administrators. Journal of Research and Development in Education, 22(2), 62-69.

Rosenholtz, S. J. (1989). Teachers' workplace: The social organization of schools. New York: Teachers College Press.

Siah, P. C., Ong, S. B. C., Tan, S. M., \& Sim, C. P. (2015). Perception on Chinese values: A comparison of Chinese secondary students studying at national secondary schools and Chinese independent schools in Malaysia. The Social Science Journal, 52(1), 62-68. doi:10.1016/j.soscij.2014.08.006 
Solansky, S., Gupta, V., \& Wang, J. (2017). Ideal and Confucian implicit leadership profiles in China. Leadership \& Organization Development Journal, 38(2), 164177. doi:10.1108/LODJ-06-2015-0114

Somech, A., \& Bogler, R. (2002). Antecedents and consequences of teacher organizational and professional commitment. Educational Administration Quarterly, 38(4), 555-577. doi: 10.1177/001316102237672

Tjeldvoll, A. (2011). Change leadership in universities: The Confucian dimension. Journal of Higher Education Policy and Management, 33(3), 219-230. doi:10.1080/1360080x.2011.564997

The Malaysian Administrative Modernisation and Management Planning Unit [MAMPU]. (n.d.). Getting formal education: Getting general information about government schools. Retrieved from https://www.malaysia.gov.my/portal/content/29468

Thien, L. M. (2019). Distributive leadership functions, readiness for change and teachers' affective commitment to change: A partial least squares analysis. Sage Open, 9(2). doi:10.1177/2158244019846209

Thien, L. M., Razak, N. A., \& Ramayah, T. (2014). Validating teacher commitment scale using a Malaysian sample. Sage Open, 4(2). doi:10.1177/2158244014536744

Thien, L. M., \& Razak, N. A. (2014). Teacher commitment: A comparative study of Malaysian ethnic groups in three types of primary Schools. Social Psychology of Education, 17, 307-326. doi:10.1007/s11218-013-9242-6

Truong, T. D., \& Hallinger, P. (2017). Exploring cultural context and school leadership: conceptualizing an indigenous model of có uy school leadership in Vietnam. International Journal of Leadership in Education, 20(5), 539-561. doi:10.1080/13603124.2015.1105388

Wang, X. (2011). A conceptual and empirical investigation of leader virtues and virtuous leadership (Doctoral dissertation). McMaster University, Ontario.

Wang, L. H., Gurr, D., \& Drysdale, L. (2016). Successful school leadership: Case studies of four Singapore primary schools. Journal of Educational Administration, 54(3), 270-287. doi: 10.1108/JEA-03-2015-0022

$\mathrm{Xu}, \mathrm{K}$. (2011). An empirical study of Confucianism: Measuring Chinese academic leadership. Management Communication Quarterly, 25(4), 644-662.

Zheng, X., Yin, H., \& Li, Z. (2019). Exploring the relationships among instructional leadership, professional learning community and teacher self-efficacy in China. Educational Management Administration \& Leadership, 47(6), 843859. doi:10.1177/1741143218764176 